

\section{COMMENTARY: PUSH AND PULL FACTORS AND THE REINTEGRATION OF CHILDREN IN THE DRC}

\section{By Aneeta Williams}

\section{International Consultant (formerly Head of \\ Programme Quality, War Child UK)}

The recruitment and use of child soldiers creates a lasting tear in society, and none so severely as the civil war in the Democratic Republic of Congo. It is estimated that there are 310,000 children who are associated or formerly associated with armed forces or groups. Many (both girls and boys) experience sexual violence prior, during and/or following their association. As Arpita Mitra described in her paper, the scale of the tragedy is both widespread and brutal. She argues that despite the huge sums of financial assistance poured into the area for Disarmament, Demobilization, and Reintegration (DDR) programming, the implementation has failed to meet its goals.

The author argues that the predominant weakness in the DDR programmes is that it lacks the effective and sustained psycho-social support for children to overcome the trauma of being exposed to violent conflict. This is particularly important for young children who, because of 
their lack of capacity to understand the enormity of the atrocities, were influenced or forced to commit horrific acts of violence themselves. The lack of psycho-social support provision during and in the follow-up to the DRR is a fatal flaw, particularly as children suffer from complex psychological malfunctioning.

Some other key reasons include: the "one weapon, one child" rule which restricted the number of children eligible for DRR programming. This effectively excluded non-combatants such as child brides, cooks, and servants who were predominantly female. Inevitably there is a gender-bias towards boys who tend to be pushed to the front-line and are armed; the lack of sustained community engagement and possible resentment since the programme is seen as being counter-productive, as it provides children vocational and skills-building for an almost non-existent job market; and reintegration kits and financial payments to children formerly associated with armed groups were often seen as an incentive for recruitment or re-recruitment.

The above points reflect the fact that reintegration is a 2-way process between the children and the community that should be undertaken by more traditional routes including cleansing ceremonies requesting forgiveness. A recent report by War Child, "Tug of War," these findings and takes a deeper dive into the "push" (negative conditions or circumstances) and "pull" (positive rewards or incentives) factors affecting recruitment and re-recruitment of children into armed groups in DRC through qualitative research in North and South Kivu. It shows that the linkages between poorly executed reintegration and inhospitable conditions within communities can lead to an increased risk of re-recruitment.

The report mentions further challenges to the DDR programme, illustrating how children (once recruited) vacillate between the armed groups and community, trying to establish which of the two will offer them the best opportunity. For example, in North and South Kivu children are often disappointed by what they come back to in the community. Life in the armed groups may be physically more challenging and more brutal, but it presents an opportunity to eat better and live better (albeit through stealing) than in the community. The attempts to provide economic or vocational packages are rendered moot if there is no market to return to. This is compounded by stigma. Community members are often suspicious of boys and girls returning from armed groups, blaming them for any wrong that happens in the community and making them feel unwelcome. Children risk being arrested or imprisoned if they return to the community without a demobilisation certificate or a weapon and indeed have been severely beaten by FARDC soldiers or police - so they rarely escape their circumstances. There is also an added cost to the family, in many cases because parents are required to pay bribes

1 War Child UK and War Child Holland, "Tug of War: Children in Armed Groups in DRC - A study on the push and pull factors on influencing armed groups in DRC" (May, 2018) https://www.warchild. org.uk/sites/default/files/link-files/Tug-Of-War_Children_in_Armed_Groups_in_DRC.pdf. 
to chiefs, local authorities and security services at every step of the demobilisation process to secure the release of their child - to ensure they are not arrested or imprisoned or caught by the armed group for having escaped.

The War Child report suggests a multi-pronged approach to DRR programming. The challenge of reintegration should include advocating against corruption by different state and non-state actors, and stigma, violence and harassment of child returnees in the community. Prevention is key, for example providing parents income-earning activities to support their children to stay in school - found to be the biggest deterrent to participation in a militia. Due to their vulnerabilities, girls and mothers with young children in the DRR programme should be transferred to temporary host families or Interim Care Centres (ICC) immediately, which have received training to care for such children. Reintegration should take between 3-5 years and there is a need to develop a comprehensive, well-planned and implemented reintegration programme. Finally, it recommends the "one plus approach" - providing a child leaving armed groups and another orphaned or vulnerable child equal opportunity in the DDR programme to reduce tensions and stigma within the community.

While it is acknowledged that the DDR program in the Democratic Republic of Congo represents an enormous investment, it is also, sadly, just a start. The goal of DDR programming is to bring the child and society back together in healthy environment. This requires a long-term and sustained investment that addresses the needs of both the child and the community.

Aneeta Williams is a former lawyer turned international development and humanitarian practitioner. Her specialisms include International Human Rights and International Humanitarian Law, Gender and SGBV, Safeguarding and Protection, Access to Justice for Victims and Juveniles; Accountability, Policy and Advocacy. Over 15 years, she has advised, supported and trained INGOs, networks and faith-based organisations across the globe to develop robust safeguarding policies, procedures, monitoring tools and investigation guidelines based on international standards and good practice. Over the years she has worked with UNICEF, The Children's Society, Surrey Children's Services, Tearfund, Erikshjalpen, Plan International, World Vision UK, Progressio, Mothers Union and War Child UK among others.

She is an accredited Preventing Sexual Exploitation and Abuse (PSEA) Investigator under the Core Humanitarian Standard Alliance and has undertaken several investigations. She is a founding Board member of the Keeping Children Safe Coalition and supported the development and implementation of international standards and resources on child safeguarding. As Preventing Sexual Violence Initiative (PSVI) Expert, Aneeta has worked on the documentation and investigation of sexual violence of the refugee crisis in the Middle East and East Africa.

She has written several articles, conference papers, resources, polices and publications on safeguarding and protection of children and vulnerable groups and is a regular invited speaker at law schools and at events. 